\title{
Independent Risk Factors for Sepsis-Associated Cardiac Arrest in Patients with Septic Shock
}

\author{
Won Soek Yang ${ }^{1}$, Youn-Jung Kim ${ }^{2}$, Seung Mok Ryoo ${ }^{2}$ and Won Young Kim ${ }^{2, *}$ (i) \\ 1 Department of Emergency Medicine, Hallym University Sacred Heart Hospital, Hallym University College of \\ Medicine, Anyang 24252, Korea; wsyang@hallym.or.kr \\ 2 Asan Medical Center, Department of Emergency Medicine, University of Ulsan College of Medicine, \\ Seoul 44610, Korea; yjkim.em@gmail.com (Y.-J.K.); chrisryoo@naver.com (S.M.R.) \\ * Correspondence: wonpia73@naver.com
}

check for updates

Citation: Yang, W.S.; Kim, Y.-J.; Ryoo, S.M.; Kim, W.Y. Independent Risk Factors for Sepsis-Associated Cardiac Arrest in Patients with Septic Shock. Int. J. Environ. Res. Public Health 2021, 18, 4971. https://doi.org/10.3390/ ijerph18094971

Academic Editor: Paul B. Tchounwou

Received: 7 April 2021

Accepted: 4 May 2021

Published: 7 May 2021

Publisher's Note: MDPI stays neutral with regard to jurisdictional claims in published maps and institutional affiliations.

Copyright: (c) 2021 by the authors. Licensee MDPI, Basel, Switzerland. This article is an open access article distributed under the terms and conditions of the Creative Commons Attribution (CC BY) license (https:// creativecommons.org/licenses/by/ $4.0 /)$.

\begin{abstract}
The clinical characteristics and laboratory values of patients with septic shock who experience in-hospital cardiac arrest (IHCA) have not been well studied. This study aimed to evaluate the prevalence of IHCA after admission into the emergency department and to identify the factors that increase the risk of IHCA in septic shock patients. This observational cohort study used a prospective registry of septic shock patients and was conducted at the emergency department of a universityaffiliated hospital. The data of 887 adult (age $\geq 18$ years) septic shock (defined using the Sepsis- 3 criteria) patients who were treated with a protocol-driven resuscitation bundle therapy and were admitted to the intensive care unit between January 2010 and September 2018 were analyzed. The primary endpoint was the occurrence of sepsis-associated cardiac arrest. The patient mean age was 65 years, and $61.8 \%$ were men. Sepsis-associated cardiac arrest occurred in $25.3 \%$ of patients $(n=224)$. The 28-day survival rate after cardiac arrest was $6.7 \%$. Multivariate logistic regression identified chronic pulmonary disease (odds ratio (OR) 2.06), hypertension (OR 0.48), unknown infection source (OR 1.82), a hepatobiliary infection source (OR 0.25), C-reactive protein (OR 1.03), and serum lactate level $6 \mathrm{~h}$ from shock (OR 1.34). Considering the high mortality rate of sepsis-associated cardiac arrest after cardiopulmonary resuscitation, appropriate monitoring is required in septic shock patients with major risk factors for IHCA.
\end{abstract}

Keywords: sepsis; septic shock; cardiac arrest; mortality

\section{Introduction}

Sepsis is an infection-induced clinical syndrome. The global prevalence of sepsis is between 29.5 and $51 \%$ in multinational studies for intensive care unit patients [1,2].

In the United States, >200,000 patients experience in-hospital cardiac arrest (IHCA) yearly and only $20 \%$ of these patients are discharged alive [3-6]. In most cases (65\%), cardiac arrest has a cardiac origin; however, between $13 \%$ and $27 \%$ of cases occur in adult patients with underlying sepsis [7-9].

Considering the cardinal pathophysiologic features of sepsis, cardiopulmonary resuscitation in patients with sepsis is challenging and usually unsuccessful, with a high risk of cerebral anoxic damage $[7,8,10,11]$. Recent registry data suggest that survival from sepsis-associated IHCA has improved during the last two decades; however, patients with sepsis continue to have worse outcomes than patients without sepsis $[8,10]$. To date, few studies have specifically evaluated the risk factors for the occurrence of sepsis-associated IHCA. Moreover, most of the studies on the epidemiology and outcomes of patients with sepsis who develop IHCA are limited by their use of data extrapolated from cardiac arrest registries, few of which specify sepsis as a subgroup of interest [4-6, 10-12]. In addition, these studies are limited by the variety of sepsis-related diagnoses and changes in the definition of sepsis [10-16]. The aim of this study was to evaluate the prevalence of IHCA in septic shock patients after admission into the emergency department and to determine 
the factors associated with an increased risk of IHCA in patients with septic shock, as defined by the Sepsis- 3 criteria.

\section{Methods}

\subsection{Study Design and Population}

This retrospective cohort study, based on a prospective registry of septic shock, was conducted at the emergency department of a university-affiliated hospital in South Korea with an annual patient volume of $>110,000$. This registry included all consecutive adult (age $\geq 18$ years) patients with septic shock who were diagnosed in the emergency department of Asan Medical Center since January 2010. The registry contains demographic findings and clinical features, including laboratory results, details of treatment, and prognosis such as mortality. Septic shock was defined according to the Sepsis-3 criteria as follows: refractory hypotension (systolic blood pressure $<90 \mathrm{mmHg}$, mean arterial pressure $<65 \mathrm{mmHg}$, or systolic blood pressure decrease $>40 \mathrm{mmHg}$ ) and hypoperfusion (serum lactate level $\geq 4 \mathrm{mmol} / \mathrm{L}$ ) after adequate intravenous fluid challenges (20-30 mL/ kg). Patients who were admitted to the intensive care unit between January 2010 and September 2018 were included and analyzed for the occurrence of cardiac arrest during hospitalization. All patients were treated for septic shock with a protocol-driven resuscitation bundle therapy, including crystalloid administration, blood culture, broad-spectrum antibiotics, vasopressors, lung-protective ventilation, glucocorticoids, and surgical intervention (if indicated). Patients transferred to another hospital during treatment and those who refused resuscitation treatment were excluded (Figure 1).

\section{Septic shock (defined by Sepsis-3 criteria) in ED}

$(n=1555)$

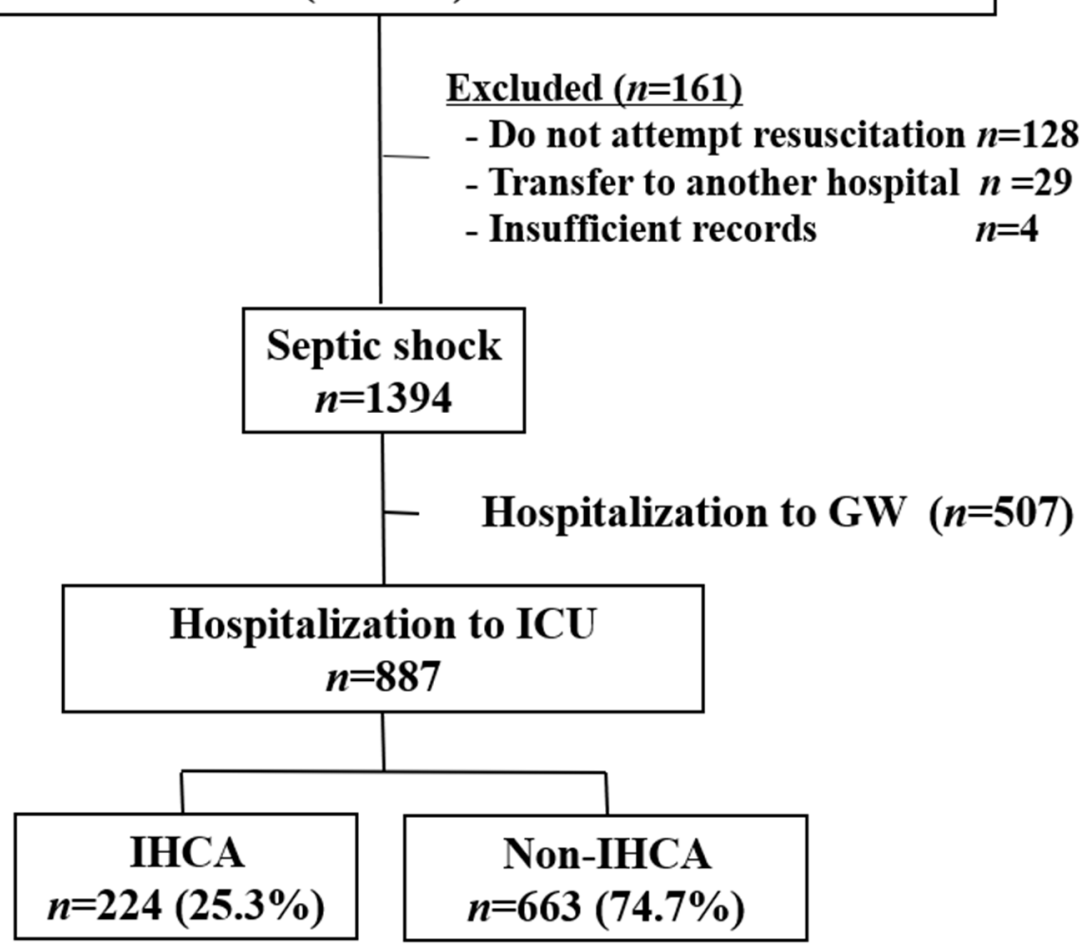

Figure 1. Flowchart of patient inclusion. Abbreviations: ED, emergency department; GW, general ward; ICU, intensive care unit; IHCA, in-hospital cardiac arrest.

This study was approved by the research ethics committee of the hospital, which waived the requirement for informed consent because of the retrospective design. 


\subsection{Data Collection}

Demographic and clinical data, including age, sex, comorbidities, vital signs at septic shock diagnosis, source of infection, laboratory test findings, initial serum lactate level, and Sequential Organ Failure Assessment (SOFA) scores, were collected. Initial serum lactate levels were measured at shock recognition, and a follow-up measurement was performed $6 \mathrm{~h}$ after the initial measurement. The primary endpoint was the occurrence of sepsisassociated cardiac arrest, which was defined as the first event of pulseless cardiac activity of any cardiac rhythm occurring in septic shock patients during intensive care unit admission. If patients or family members agreed to DNR (do not resuscitate) or POLST (physician orders for life-sustaining treatment), they were excluded from the study. Patients admitted to the intensive care unit were transported to the general ward upon the improvement of the clinical symptoms of septic shock, as judged by the clinicians.

\subsection{Statistical Analysis}

The normality of data distributions was evaluated using the Kolmogorov-Smirnov test to select the appropriate parametric and nonparametric statistical methods. Categorical variables were analyzed using the chi-square test or Fisher's exact test. Continuous variables were expressed as medians (25th-75th percentile) and were analyzed using the Mann-Whitney U test. We used age, sex, all variables in baseline and clinical characteristics, and laboratory findings for univariate logistic regression analysis of risk factors for the occurrence of IHCA. Considering the problem of collinearity, we analyzed each variable separately without using a SOFA score. Independent risk factors associated with IHCA were evaluated using multivariate backward stepwise logistic regression after adjustment for confounding factors, defined as factors found to be significant in univariate analysis based on a type I error of 0.1. We presented the odds ratios (ORs) with $95 \%$ confidence intervals (CIs) for each model. The SPSS statistical software package for Windows (version 26.0; SPSS Inc., Chicago, IL, USA) was used for all analyses.

\section{Results}

Of the 1555 patients with septic shock during the study period, 128 patients with a DNR order, 29 patients who were transferred to another hospital, and 4 patients with insufficient records were excluded. The remaining 1394 patients were enrolled. The rest of the 887 patients with septic shock who were admitted to the intensive care unit were finally included. The incidence of IHCA in our patients was $25.3 \%(n=224)$ (Figure 1$)$. The median time from emergency department visit to the occurrence of cardiac arrest was 4 (2-12) days.

\subsection{Clinical Characteristics}

The baseline and clinical characteristics of septic shock patients who developed IHCA and those who did not are summarized in Table 1. The median age of the patients was 65 years, and $61.8 \%$ of the patients were men. Among the comorbidities, chronic pulmonary disease was more frequent in the IHCA group $(12.9 \%$ vs. $8.6 \%, p=0.015)$. Among the vital signs of shock recognition, respiration rate was higher in the IHCA group (22 (20-28) breaths/ $\mathrm{min})$ than in the non-IHCA group $(20(20-26)$ breaths $/ \mathrm{min})(p=0.031)$. The hepatobiliary tract and urinary tract were more frequently identified as sources of infection in the non-IHCA group ( $25.8 \%$ vs. $12.5 \%$, p < 0.001; $11.9 \%$ vs. $5.4 \%, p=0.005)$. An unknown infection source was more frequent in the IHCA group (15.2\% vs. $5.8 \%$, $p<0.001)$, and the SOFA score at day one was significantly higher in the IHCA group $(10(8-13)$ vs. $9(6-11), \mathrm{p}<0.001)$. 
Table 1. Comparison of baseline and clinical characteristics between the IHCA and non-IHCA groups.

\begin{tabular}{|c|c|c|c|c|}
\hline Variables & $\begin{array}{c}\text { Total } \\
\text { Patients } \\
(n=887)\end{array}$ & $\begin{array}{c}\text { Non-IHCA } \\
\text { Group } \\
(n=663)\end{array}$ & $\begin{array}{l}\text { IHCA Group } \\
\quad(n=224)\end{array}$ & $p$-Value ${ }^{\mathrm{c}}$ \\
\hline Age, years & $65.0 \pm 12.6$ & $65.2 \pm 12.5$ & $64.6 \pm 12.8$ & 0.951 \\
\hline Sex, male & $548(61.8)$ & $410(62.0)$ & $138(61.3)$ & 0.558 \\
\hline \multicolumn{5}{|l|}{ Comorbidities } \\
\hline Hypertension & $307(34.6)$ & $241(36.4)$ & $66(29.3)$ & 0.055 \\
\hline Diabetes & $245(27.6)$ & $191(28.9)$ & $54(24.0)$ & 0.163 \\
\hline Coronary disease & $86(9.7)$ & $57(8.6)$ & $29(12.9)$ & 0.083 \\
\hline $\begin{array}{l}\text { Chronic pulmonary } \\
\text { disease }\end{array}$ & $144(16.3)$ & $95(14.4)$ & $49(21.8)$ & 0.015 \\
\hline Liver cirrhosis & $138(15.6)$ & $104(15.7)$ & $34(15.1)$ & 0.856 \\
\hline Chronic renal failure & $66(7.4)$ & $49(7.4)$ & $17(7.6)$ & 0.922 \\
\hline Stroke & $49(5.5)$ & $40(6.0)$ & $9(4.0)$ & 0.254 \\
\hline Active Malignancy $^{a}$ & $384(43.3)$ & $293(44.2)$ & $91(40.6)$ & 0.313 \\
\hline \multicolumn{5}{|c|}{ Vital signs at shock recognition } \\
\hline $\begin{array}{c}\text { MAP, } \\
\text { mmHg } \\
\text { Pulse }\end{array}$ & $60(53-66)$ & $60(53-66)$ & $59(51-67)$ & 0.526 \\
\hline $\begin{array}{l}\text { rate, } \\
\text { breaths/min }\end{array}$ & $111(93-126)$ & $110(93-126)$ & $112(94-126)$ & 0.888 \\
\hline $\begin{array}{l}\text { Body } \\
\text { temperature, } \\
{ }^{\circ} \mathrm{C}\end{array}$ & $37.5(36.6-38.3)$ & $\begin{array}{c}37.6 \\
(36.7-38.4)\end{array}$ & $\begin{array}{c}37.1 \\
(36.4-38.1)\end{array}$ & 0.136 \\
\hline GCS & $15(12-15)$ & $15(15-15)$ & $15(3-15)$ & 0.050 \\
\hline \multicolumn{5}{|l|}{ Source of sepsis } \\
\hline Lung & $286(32.2)$ & $203(30.6)$ & $83(37.1)$ & 0.083 \\
\hline Gastrointestinal tract & $132(14.9)$ & $99(14.9)$ & $33(14.7)$ & 0.942 \\
\hline Hepatobiliary tract & $199(22.4)$ & $171(25.8)$ & $28(12.5)$ & $<0.001$ \\
\hline Urinary tract & $91(10.3)$ & $79(11.9)$ & $12(5.4)$ & 0.005 \\
\hline Bloodstream & $50(5.6)$ & $32(4.8)$ & $18(8.0)$ & 0.092 \\
\hline Soft-tissue infection & $39(4.4)$ & $30(4.5)$ & $9(4.0)$ & 0.852 \\
\hline Unknown & $73(8.2)$ & $39(5.8)$ & $34(15.2)$ & $<0.001$ \\
\hline Others ${ }^{b}$ & $17(1.9)$ & $10(1.5)$ & $7(3.1)$ & 0.156 \\
\hline \multicolumn{5}{|l|}{ Severity } \\
\hline SOFA score (day 1) & $9(7-12)$ & $9(6-11)$ & $10(8-13)$ & $<0.001$ \\
\hline
\end{tabular}

a The Haemostasis and Malignancy Scientific and Standardization Committee defines "active cancer" as cancer diagnosed within the previous six months; recurrent, regionally advanced, or metastatic cancer; cancer for which treatment had been administered within six months; or hematological cancer that is not in complete remission. ${ }^{b}$ Other sources of infection included the central nervous system, catheter, and infectious endocarditis. ${ }^{c}$ The $p$-value of this table was calculated from chi-square test or Fisher's exact test for categorical variables and student T-test or Mann-Whitney U test for continuous variables. Values are expressed as mean \pm standard deviation, median (interquartile range), or number (\%). Statistically significant p-values are indicated in bold. Abbreviations: MAP, mean arterial pressure; GCS, Glasgow coma scale; SOFA, Sequential Organ Failure Assessment.

Table 2 compares the laboratory findings between septic shock patients with and without IHCA. Patients with IHCA had significantly higher serum levels of creatinine, aspartate aminotransferase, $\mathrm{C}$-reactive protein, lactate at shock recognition, and lactate at $6 \mathrm{~h}$ than patients without IHCA (Table 2).

Table 3 compares the treatment and clinical outcomes between septic shock patients with and without IHCA. A significantly higher use of steroid and renal replacement therapy was observed in IHCA patients. The duration of mechanical ventilation was longer in patients who developed IHCA. Moreover, the rate of mortality at 28 days was significantly higher in the IHCA group $(93.3 \%)$ than in the non-IHCA group $(5 \%)(p<0.001)$. The 90 -day mortality in the IHCA group was also higher than that in the non-IHCA group $(98.7 \%$ vs. $50.0 \%, p<0.001)$. 
Table 2. Comparison of laboratory findings between the IHCA and non-IHCA groups.

\begin{tabular}{|c|c|c|c|c|}
\hline Variables & $\begin{array}{l}\text { Total Patients } \\
\quad(n=887)\end{array}$ & $\begin{array}{c}\text { Non-IHCA } \\
\text { Group } \\
(n=663)\end{array}$ & $\begin{array}{l}\text { IHCA Group } \\
\quad(n=224)\end{array}$ & $p$-Value ${ }^{\text {a }}$ \\
\hline White blood cell, $\times 10^{3} / \mathrm{L}$ & $10.6(4.3-19.2)$ & $11.3(5.3-20.0)$ & $8.15(2.3-17.4)$ & 0.191 \\
\hline Hemoglobin, g/dL & $11.2(9.4-13.0)$ & $11.3 \pm 2.8$ & $11.1 \pm 2.8$ & 0.196 \\
\hline Platelets, $\times 10^{3} / \mathrm{L}$ & $140(70-213)$ & $147(78-222)$ & $120(50-138)$ & 0.015 \\
\hline Sodium, $\mathrm{mmol} / \mathrm{L}$ & 135 (131-138) & 135 (131-138) & 135 (130-138) & 0.930 \\
\hline Potassium, mmol/L & $4.2(3.7-4.8)$ & $4.1(3.7-4.7)$ & $4.4(3.8-5.0)$ & 0.170 \\
\hline Chloride, mmol/L & $99(95-103)$ & $99(95-103)$ & $99(94-103)$ & 0.578 \\
\hline Creatinine, $\mathrm{mg} / \mathrm{dL}$ & $1.6(1.1-2.7)$ & $1.5(1.0-2.6)$ & $1.9(1.3-3.0)$ & 0.032 \\
\hline AST, U/L & 47 (29-97) & $46(29-92)$ & $49(28-133)$ & 0.018 \\
\hline $\mathrm{ALT}, \mathrm{U} / \mathrm{L}$ & $30(17-62)$ & $30(18-62)$ & $28(17-62)$ & 0.096 \\
\hline Albumin, g/dL & $2.6(2.2-3.1)$ & $2.7(2.2-3.2)$ & $2.8(1.9-2.8)$ & 0.423 \\
\hline Total bilirubin, $\mathrm{mg} / \mathrm{dL}$ & $1.2(0.7-2.5)$ & $1.3(0.8-2.5)$ & $1.2(0.7-2.5)$ & 0.128 \\
\hline Prothrombin time, INR & 1.31 (1.15-1.58) & 1.29 (1.14-1.53) & $1.41(1.21-1.77)$ & 0.982 \\
\hline $\mathrm{CRP}, \mathrm{mg} / \mathrm{dL}$ & $13.2(4.9-23.17)$ & $11.8(4.2-21.6)$ & $16.7(7.1-25.7)$ & $<0.001$ \\
\hline Procalcitonin, $\mathrm{mmol} / \mathrm{L}$ & $15.8(3.1-44.0)$ & $15.8(3.2-45.6)$ & $15.8(2.7-38.3)$ & 0.341 \\
\hline D-dimer, mcg/mL & $5.3(2.7-12.0)$ & $5.1(2.5-11.6)$ & $6.5(3.2-13.9)$ & 0.810 \\
\hline Troponin-I, ng/mL & $0.05(0.02-0.16)$ & $0.05(0.01-0.15)$ & $0.05(0.02-0.18)$ & 0.613 \\
\hline $\mathrm{pH}$ & $7.42(7.34-7.47)$ & 7.43(7.35-7.47) & 7.38(7.24-7.46) & 0.327 \\
\hline $\mathrm{PCO}_{2}, \mathrm{mmHg}$ & $27(22-33)$ & $27(22-32)$ & $28(22-33)$ & 0.422 \\
\hline $\mathrm{PO}_{2}, \mathrm{mmHg}$ & $75(60-92)$ & $75(62-92)$ & 72 (57-92) & 0.922 \\
\hline Bicarbonate, $\mathrm{mmol} / \mathrm{L}$ & $18(14-22)$ & $19(15-22)$ & $17(12-21)$ & $<0.003$ \\
\hline Initial lactate, $\mathrm{mmol} / \mathrm{L}$ & $4.6(3.1-7.2)$ & $4.4(3.0-6.3)$ & $6.1(3.6-9.7)$ & $<0.001$ \\
\hline Lactate after $6 \mathrm{~h}, \mathrm{mmol} / \mathrm{L}$ & $3.9(2.4-5.9)$ & $3.4(2.2-5.0)$ & $5.7(3.1-9.2)$ & $<0.001$ \\
\hline Lactate normalization in $6 \mathrm{~h}$ & $152(17.1)$ & $128(19.3)$ & $24(10.7)$ & $<0.001$ \\
\hline
\end{tabular}

a The $p$-value of this table was calculated from chi-square test or Fisher's exact test for categorical variables and student T-test or Mann-Whitney $U$ test for continuous variables. Values are expressed as mean \pm standard deviation, median (interquartile range), or number (\%). : Statistically significant $p$-values are indicated in bold Abbreviations: AST, aspartate aminotransferase; ALT, alanine transaminase; INR, international normalized ratio; $\mathrm{CRP}$, C-reactive protein; $\mathrm{PO}_{2}$, partial pressure of oxygen; $\mathrm{PCO}_{2}$, partial pressure of carbon dioxide.

Table 3. Comparison of treatment and clinical outcomes between the IHCA and non-IHCA groups.

\begin{tabular}{|c|c|c|c|c|}
\hline Variables & $\begin{array}{l}\text { Total Patients } \\
\quad(n=887)\end{array}$ & $\begin{array}{c}\text { Non-IHCA } \\
\text { Group } \\
(n=663)\end{array}$ & $\begin{array}{l}\text { IHCA Group } \\
\quad(n=224)\end{array}$ & $p$-Value ${ }^{\text {a }}$ \\
\hline Steroid treatment & $308(34.7)$ & $195(29.4)$ & $113(50.4)$ & $<0.001$ \\
\hline RRT & $313(35.3)$ & $174(26.2)$ & $139(62.1)$ & $<0.001$ \\
\hline $\begin{array}{l}\text { Duration of mechanical } \\
\text { ventilation, days }\end{array}$ & $2(0-8)$ & $0(0-7)$ & $3(2-12)$ & 0.010 \\
\hline $\begin{array}{l}\text { Duration of ICU stay, } \\
\text { days }\end{array}$ & $5(3-10)$ & $5(3-10)$ & $4(2-12)$ & 0.721 \\
\hline Mortality at 28 days & $242(27.3)$ & $33(5.0)$ & $209(93.3)$ & $<0.001$ \\
\hline Mortality at 90 days & $532(60.0)$ & $331(50.0)$ & $221(98.7)$ & $<0.001$ \\
\hline
\end{tabular}

a The $p$-value of this table was calculated from chi-square test or Fisher's exact test for categorical variables and student T-test or Mann-Whitney $U$ test for continuous variables. Values are expressed as mean \pm standard deviation, median (interquartile range), or number $(\%)$. : Statistically significant $p$-values are indicated in bold. Abbreviations: RRT, renal replacement therapy; ICU, intensive care unit.

\subsection{Associated Risk Factors for the Development of IHCA}

The results of univariate and multivariate logistic regression analyses performed to identify the risk factors for the development of IHCA in patients with septic shock are presented in Table 4. Age, sex, and all variables in Table 1 and 2 were analyzed for univariate logistic regression analysis of risk factors for the occurrence of IHCA. All variables with $p$-values less than 0.1 are presented in Table 4; the rest were omitted.

Variables with $p<0.1$ in the univariate analysis were adjusted in the multivariable analysis. In multivariate logistic regression analysis, the following factors were found to be independently associated with the development of IHCA: preexisting hypertension (OR $0.48,95 \%$ CI 0.30-0.80), preexisting chronic pulmonary disease (OR 2.01, 95\% CI 1.19-3.58), hepatobiliary infection source (OR $0.25,95 \%$ CI $0.11-0.54)$, unknown infection source (OR 
$1.82,95 \%$ CI 1.01-3.47), serum level of C-reactive protein (OR 1.03, 95\% CI 1.01-1.04), and serum level of lactate $6 \mathrm{~h}$ from shock recognition (OR 1.34, 95\% CI 1.22-1.47).

Table 4. Logistic regression analysis of risk factors associated with IHCA in septic shock patients.

\begin{tabular}{|c|c|c|c|c|c|c|}
\hline \multirow{2}{*}{ Variable } & \multicolumn{3}{|c|}{ Univariate Analysis } & \multicolumn{3}{|c|}{ Multivariate Analysis } \\
\hline & OR & $95 \%$ CI & $p$-Value ${ }^{a}$ & OR & $95 \%$ CI & $p$-Value ${ }^{b}$ \\
\hline Age & 0.99 & $0.725-1.352$ & 0.951 & & & \\
\hline Sex & 0.996 & $0.985-1.008$ & 0.558 & & & \\
\hline Hypertension & 0.731 & $0.527-1.015$ & 0.062 & 0.484 & $0.295-0.796$ & 0.004 \\
\hline Chronic pulmonary disease & 1.674 & $1.140-2.458$ & 0.009 & 2.058 & $1.185-3.575$ & 0.010 \\
\hline GCS & 0.953 & $0.092-1.007$ & 0.085 & & & \\
\hline Pulmonary infection source & 1.426 & $1.039-1.957$ & 0.028 & & & \\
\hline Hepatobiliary infection source & 0.394 & $0.254-0.611$ & $<0.001$ & 0.246 & $0.113-0.536$ & $<0.001$ \\
\hline Urinary tract infection source & 0.389 & $0.203-0.746$ & 0.004 & & & \\
\hline Unknown infection source & 2.842 & $1.734-4.656$ & $<0.001$ & 1.820 & $1.012-3.472$ & 0.043 \\
\hline Platelet count & 0.998 & 0.997-1.000 & 0.015 & & & \\
\hline Creatinine & 1.080 & $1.003-1.163$ & 0.042 & & & \\
\hline AST & 1.001 & $1.000-1.001$ & 0.005 & & & \\
\hline CRP & 1.027 & $1.014-1.040$ & $<0.001$ & 1.028 & $1.005-1.042$ & 0.010 \\
\hline Bicarbonate & 0.946 & $0.920-0.972$ & $<0.001$ & & & \\
\hline Initial lactate & 1.173 & $1.122-1.227$ & $<0.001$ & & & \\
\hline Lactate after $6 \mathrm{~h}$ & 1.288 & $1.219-1.360$ & $<0.001$ & 1.338 & $1.221-1.465$ & $<0.001$ \\
\hline
\end{tabular}

${ }^{a}$ The $p$-Value from univariate logistic analysis of risk factors for IHCA. ${ }^{\mathrm{b}}$ The $p$-Value from multivariate logistic analysis of risk factors for IHCA. : Statistically significant $p$-values are indicated in bold. Abbreviations: GCS, Glasgow coma scale; AST, aspartate aminotransferase; CRP, C-reactive protein.

\section{Discussion}

Although coronary disease is the main etiology of cardiac arrest, approximately 13$27 \%$ of patients experience cardiac arrest related to infection such as sepsis, which has an even worse prognosis [5,8]. In this study, we observed the occurrence of IHCA in patients with septic shock diagnosed in the emergency department and admitted to the intensive care unit. We compared the clinical characteristics of the IHCA and non-IHCA groups. Characteristics such as chronic pulmonary disease, an unknown infection source, and serum lactate level $6 \mathrm{~h}$ from shock recognition had high odds for the occurrence of sepsis-associated IHCA, whereas a history of hypertension and a hepatobiliary infection source were associated with low odds for the development of sepsis-associated IHCA. These findings have potential clinical implications, such as in the early identification of high-risk patients with septic shock who would require intensive monitoring or aggressive management to prevent IHCA in the intensive care unit.

The 28-day mortality rate of septic shock patients admitted to the intensive care unit was $27.3 \%$ in this study. This is consistent with the mortality rate in the ANZICS cohort $(22.0 \%)$ and that in other studies [17-19]. Although most of the previous studies on septic shock selected mortality as a primary outcome, the occurrence of IHCA does not have the same meaning as mortality. One early study included 73 patients with sepsis-associated IHCA, of whom $45 \%$ were initially resuscitated but only one patient survived to discharge compared with $7.8 \%$ of patients without sepsis who survived to discharge [16]. However, more recent data have shown that the survival rate from sepsisassociated IHCA has improved from $7.6 \%$ to $9.3 \%[10,11]$. This is consistent with the present result that $6.7 \%$ of patients with sepsis-associated IHCA survived up to 28 days. Our study has several strengths as compared with previous studies. First, considering that the most common cause of death from septic shock is the withdrawal of treatment [20], our results can reflect the natural course of septic shock because withdrawing life support treatment from resuscitated patients is legally prohibited in South Korea. In addition, to our knowledge, almost no data exist on the occurrence of sepsis-associated IHCA from septic shock registries using the Sepsis-3 definition. Previous epidemiological data on 
sepsis-associated IHCA were derived from cardiac arrest registries that report only the proportion of cardiac arrest cases among patients with sepsis or related disease categories.

In previous studies, serum lactate level was related to mortality in septic shock patients [21-24]. In our study, the initial serum lactate level was a statistically significant factor in the occurrence of IHCA in univariate analysis but did not reach statistical significance in multivariate analysis. An increased serum lactate level indicates that the patient did not recover from shock despite receiving the best treatment in the intensive care unit and, thus, has the possibility of developing IHCA. Few previous studies performed a serial follow-up of serum lactate level to predict mortality in septic shock patients $[18,25]$. Serial testing of serum lactate level may be necessary to check the response to treatment and to predict the occurrence of unexpected IHCA.

Previous studies reported the correlation between serum C-reactive protein level and mortality of sepsis patients [26-30]. This is consistent with the present results, although we strictly selected the septic shock patients who met Sepsis-3 and were hospitalized in the intensive care unit.

In accordance with previous studies, patients with an unknown source of sepsis or a bacteremia infection had higher mortality rates than patients with known infection sources [31-34]. It is presumed that the difficulty in selecting the appropriate antibiotics and in the application of proper procedures and surgical intervention may have affected the treatment and prognosis.

This study had some notable limitations. Owing to the retrospective design, our study is limited by factors inherent in the collection, analysis, and interpretation of retrospective data despite the use of a prospective septic shock registry. In addition, although our cohort comprised a considerable number of strictly selected septic shock patients admitted to the intensive care unit from the emergency department, this study was conducted at a single institution, which limits the generalization of our results to other institutions or to the general population.

\section{Conclusions}

Cardiac arrest occurred after hospitalization in a quarter of septic shock patients in this study. Considering the high rates of mortality from sepsis-associated cardiac arrest after cardiopulmonary resuscitation, appropriate monitoring is required in patients with septic shock with major risk factors for cardiac arrest.

Author Contributions: Conceptualization, W.Y.K. and W.S.Y.; methodology, W.Y.K. and W.S.Y.; software, W.Y.K. and W.S.Y.; validation, W.Y.K., W.S.Y., Y.-J.K., and S.M.R.; formal analysis, W.Y.K. and W.S.Y.; investigation, W.S.Y.; resources, W.Y.K.; data curation, W.Y.K. and W.S.Y.; writing-original draft preparation, W.S.Y.; writing—review and editing, W.Y.K., W.S.Y., Y.-J.K., and S.M.R.; visualization, W.Y.K. and W.S.Y.; supervision, W.Y.K.; project administration, W.Y.K.; funding acquisition, W.Y.K. All authors have read and agreed to the published version of the manuscript.

Funding: This research received no external funding.

Institutional Review Board Statement: The study was conducted according to the guidelines of the Declaration of Helsinki, and approved by the Institutional Review Board of the Asan Medical Center (no. 2015-1253).

Informed Consent Statement: Patient consent was waived due to retrospective nature of the study.

Data Availability Statement: Not applicable.

Conflicts of Interest: The authors declare no conflict of interest. 


\section{References}

1. Farrah, K.; McIntyre, L.; Doig, C.J.; Talarico, R.; Taljaard, M.; Krahn, M.; Fergusson, D.; Forster, A.J.; Coyle, D.; Thavorn, K. Sepsis-Associated Mortality, Resource Use, and Healthcare Costs: A Propensity-Matched Cohort Study. Crit. Care Med. 2021, 49, 215-227. [CrossRef] [PubMed]

2. Tianyi, F.L.; Tochie, J.N.; Danwang, C.; Mbonda, A.; Temgoua, M.N.; Mapoh, S.Y.; Nkemngu, N.J.; Tallah, E.; Bigna, J.J. Global epidemiology of septic shock: A protocol for a systematic review and meta-analysis. BMJ Open 2019, 9, e032289. [CrossRef] [PubMed]

3. Nadkarni, V.M.; Larkin, G.L.; Peberdy, M.A.; Carey, S.M.; Kaye, W.; Mancini, M.E.; Nichol, G.; Lane-Truitt, T.; Potts, J.; Ornato, J.P.; et al. First Documented Rhythm and Clinical Outcome from In-Hospital Cardiac Arrest Among Children and Adults. JAMA 2006, 295, 50-57. [CrossRef] [PubMed]

4. Merchant, R.M.; Yang, L.; Becker, L.B.; Berg, R.A.; Nadkarni, V.; Nichol, G.; Carr, B.G.; Mitra, N.; Bradley, S.M.; Abella, B.S.; et al. Incidence of treated cardiac arrest in hospitalized patients in the United States. Crit. Care Med. 2011, 39, 2401-2406. [CrossRef] [PubMed]

5. Girotra, S.; Nallamothu, B.K.; Spertus, J.A.; Yan, L.; Krumholz, H.M.; Chan, P.S. Trends in Survival after In-Hospital Cardiac Arrest. N. Engl. J. Med. 2012, 367, 1912-1920. [CrossRef] [PubMed]

6. Kazaure, H.S.; Roman, S.A.; Sosa, J.A. Epidemiology and outcomes of in-hospital cardiopulmonary resuscitation in the United States, 2000-2009. Resuscitation 2013, 84, 1255-1260. [CrossRef]

7. Leoni, D.; Rello, J. Cardiac arrest among patients with infections: Causes, clinical practice and research implications. Clin. Microbiol. Infect. 2017, 23, 730-735. [CrossRef]

8. Morgan, R.W.; Fitzgerald, J.C.; Weiss, S.L.; Nadkarni, V.M.; Sutton, R.M.; Berg, R.A. Sepsis-associated in-hospital cardiac arrest: Epidemiology, pathophysiology, and potential therapies. J. Crit. Care 2017, 40, 128-135. [CrossRef]

9. Sosnowska-Mlak, O.; Curt, N.; Pinet Peralta, L.M. Survival in sudden cardiac arrest in emergency room. Crit. Care Innov. 2019, 2 , 1-10.

10. Chan, P.S.; Berg, R.A.; Spertus, J.A.; Schwamm, L.H.; Bhatt, D.L.; Fonarow, G.C.; Heidenreich, P.A.; Nallamothu, B.K.; Tang, F.; Merchant, R.M. Risk-Standardizing Survival for In-Hospital Cardiac Arrest to Facilitate Hospital Comparisons. J. Am. Coll. Cardiol. 2013, 62, 601-609. [CrossRef]

11. Larkin, G.L.; Copes, W.S.; Nathanson, B.H.; Kaye, W. Pre-resuscitation factors associated with mortality in 49,130 cases of in-hospital cardiac arrest: A report from the National Registry for Cardiopulmonary Resuscitation. Resuscitation 2010, 81, 302-311. [CrossRef]

12. Peberdy, M.A.; Kaye, W.; Ornato, J.P.; Larkin, G.L.; Nadkarni, V.; Mancini, M.E.; Berg, R.A.; Nichol, G.; Lane-Trultt, T. Cardiopulmonary resuscitation of adults in the hospital: A report of 14720 cardiac arrests from the National Registry of Cardiopulmonary Resuscitation. Resuscitation 2003, 58, 297-308. [CrossRef]

13. Matamoros, M.; Rodriguez, R.; Callejas, A.; Carranza, D.; Zeron, H.; Sanchez, C.; Del Castillo, J.; López-Herce, J. In-hospital Pediatric Cardiac Arrest in Honduras. Pediatr. Emerg. Care 2015, 31, 31-35. [CrossRef]

14. del Castillo, J.; López-Herce, J.; Cañadas, S.; Matamoros, M.; Rodríguez-Núnez, A.; Rodríguez-Calvo, A.; Carrillo, A. Cardiac arrest and resuscitation in the pediatric intensive care unit: A prospective multicenter multinational study. Resuscitation 2014, 85, 1380-1386. [CrossRef] [PubMed]

15. Rodríguez-Núñez, A.; López-Herce, J.; García, C.; Carrillo, A.; Domínguez, P.; Calvo, C.; Delgado, M.A. Effectiveness and long-term outcome of cardiopulmonary resuscitation in paediatric intensive care units in Spain. Resuscitation 2006, 71, 301-309. [CrossRef] [PubMed]

16. Taffet, G.E.; Teasdale, T.A.; Luchi, R.J. In-Hospital Cardiopulmonary Resuscitation. JAMA 1988, 260, 2069-2072. [CrossRef]

17. April, M.D.; Donaldson, C.; Tannenbaum, L.I.; Moore, T.; Aguirre, J.; Pingree, A.; Lantry, J.H. Emergency department septic shock patient mortality with refractory hypotension vs hyperlactatemia: A retrospective cohort study. Am. J. Emerg. Med. 2017, 35, 1474-1479. [CrossRef]

18. Ryoo, S.M.; Lee, J.; Lee, Y.-S.; Lee, J.H.; Lim, K.S.; Huh, J.W.; Hong, S.-B.; Lim, C.-M.; Koh, Y.; Kim, W.Y. Lactate Level Versus Lactate Clearance for Predicting Mortality in Patients With Septic Shock Defined by Sepsis-3. Crit. Care Med. 2018, 46, e489-e495. [CrossRef]

19. Kaukonen, K.-M.; Bailey, M.; Suzuki, S.; Pilcher, D.; Bellomo, R. Mortality Related to Severe Sepsis and Septic Shock Among Critically Ill Patients in Australia and New Zealand, 2000-2012. JAMA 2014, 311, 1308-1316. [CrossRef]

20. Moskowitz, A.; Omar, Y.; Chase, M.; Lokhandwala, S.; Patel, P.; Andersen, L.W.; Cocchi, M.N.; Donnino, M.W. Reasons for death in patients with sepsis and septic shock. J. Crit. Care 2017, 38, 284-288. [CrossRef]

21. Swenson, K.E.; Dziura, J.D.; Aydin, A.; Reynolds, J.; Wira, C.R., 3rd. Evaluation of a novel 5-group classification system of sepsis by vasopressor use and initial serum lactate in the emergency department. Intern. Emerg. Med. 2018, 13, 257-268. [CrossRef] [PubMed]

22. Ko, B.S.; Korean Shock Society (KoSS) Investigators; Kim, K.; Choi, S.-H.; Kang, G.H.; Shin, T.G.; Jo, Y.H.; Ryoo, S.M.; Beom, J.H.; Kwon, W.Y.; et al. Prognosis of patients excluded by the definition of septic shock based on their lactate levels after initial fluid resuscitation: A prospective multi-center observational study. Crit. Care 2018, 22, 1-7. [CrossRef] 
23. Chambers, K.A.; Park, A.Y.; Banuelos, R.C.; Darger, B.F.; Akkanti, B.H.; Macaluso, A.; Thangam, M.; Doshi, P.B. Outcomes of severe sepsis and septic shock patients after stratification by initial lactate value. World J. Emerg. Med. 2018, 9, 113-117. [CrossRef] [PubMed]

24. Liu, G.; Lv, H.; An, Y.; Wei, X.; Yi, X.; Yi, H. Surgical Intensive Care Unit, The Third Affiliated Hospital of Sun Yat-sen University, Guangzhou 510630, Guangdong, China: Early lactate levels for prediction of mortality in patients with sepsis or septic shock: A meta-analysis. Int. J. Clin. Exp. Med. 2017, 10, 37-47.

25. Ryoo, S.M.; Ahn, R.; Lee, J.; Sohn, C.H.; Seo, D.W.; Huh, J.W.; Hong, S.-B.; Lim, C.-M.; Koh, Y.; Kim, W.Y. Timing of Repeated Lactate Measurement in Patients With Septic Shock at the Emergency Department. Am. J. Med. Sci. 2018, 356, 97-102. [CrossRef]

26. Godínez-Vidal, A.R.; Alcántara-Gordillo, R.; Aguirre-Rojano, V.I.; López-Romero, S.C.; González-Calatayud, M.; González-Pérez, L.G.; Pulido-Cejudo, A.; Gracida-Mancilla, N.I. Evaluation of C-reactive protein, procalcitonin and the PCR/PCT index as indicators of mortality in abdominal sepsis. Cir. Cir. 2020, 88, 150-153.

27. Cırık, M.Ö.; Baldemir, R.; Doğanay, G.E.; Ünver, M.; Avc1, S. The 30-day mortality predictor role of c-reactive protein/albumin ratio in critically ill COPD patients. Crit. Care Innov. 2020, 3, 1-12.

28. Cui, N.; Zhang, H.; Chen, Z.; Yu, Z. Prognostic significance of PCT and CRP evaluation for adult ICU patients with sepsis and septic shock: Retrospective analysis of 59 cases. J. Int. Med. Res. 2019, 47, 1573-1579. [CrossRef]

29. Gradel, K.O.; Jensen, T.G.; Kolmos, H.J.; Pedersen, C.; Vinholt, P.J.; Lassen, A.T. Does C-reactive protein independently predict mortality in adult community-acquired bacteremia patients with known sepsis severity? APMIS 2012, 121, 835-842. [CrossRef]

30. Devran, O.; Karakurt, Z.; Adıgüzel, N.; Güngör, G.; Moçin, O.Y.; Balcı, M.K.; Celik, E.; Saltürk, C.; Takır, H.B.; Kargın, F.; et al. C-reactive protein as a predictor of mortality in patients affected with severe sepsis in intensive care unit. Multidiscip. Respir. Med. 2012, 7, 47. [CrossRef]

31. Courjon, J.; Demonchy, E.; Degand, N.; Risso, K.; Ruimy, R.; Roger, P.-M. Patients with community-acquired bacteremia of unknown origin: Clinical characteristics and usefulness of microbiological results for therapeutic issues: A single-center cohort study. Ann. Clin. Microbiol. Antimicrob. 2017, 16, 40. [CrossRef] [PubMed]

32. Contou, D.; Roux, D.; Jochmans, S.; Coudroy, R.; Guérot, E.; Grimaldi, D.; Ricome, S.; Maury, E.; Plantefève, G.; Mayaux, J.; et al. Septic shock with no diagnosis at $24 \mathrm{~h}$ : A pragmatic multicenter prospective cohort study. Crit. Care 2016, 20, 360. [CrossRef] [PubMed]

33. Marquet, K.; Liesenborgs, A.; Bergs, J.; Vleugels, A.; Claes, N. Incidence and outcome of inappropriate in-hospital empiric antibiotics for severe infection: A systematic review and meta-analysis. Crit. Care 2015, 19, 63. [CrossRef] [PubMed]

34. Hernandez, C.; Cobos-Trigueros, N.; Fehér, C.; Morata, L.; De La Calle, C.; Marco, F.; Almela, M.; Soriano, A.; Mensa, J.; Del Rio, A.; et al. Community-onset bacteraemia of unknown origin: Clinical characteristics, epidemiology and outcome. Eur. J. Clin. Microbiol. Infect. Dis. 2014, 33, 1973-1980. [CrossRef] 